\title{
IMPLEMENTASI KEBIJAKAN PROGRAM INOVASI PEMBANGUNAN DAN PEMBERDAYAAN KEWILAYAHAN (PIPPK) DI KELURAHAN PELINDUNGHEWAN KECAMATAN ASTANAANYAR KOTA BANDUNG PROVINSI JAWA BARAT
}

\author{
Oleh \\ Muhammad Try Ardian", \\ Sampara Lukman ${ }^{2}$, Layla Kurniawati ${ }^{3}$ \\ 1) Institut Pemerintahan Dalam Negeri \\ Program Magister Terapan Studi Pemerintahan Daerah Institut Pemerintahan Dalam Negeri \\ tryaldy12@gmail.com \\ ${ }^{2,3)}$ Institut Pemerintahan Dalam Negeri
}

\author{
ABSTRACT \\ "IMPLEMENTATION OF DEVELOPMENT INNOVATION POLICY PROGRAM \\ AND REGIONAL EMPOWERMENT (PIPPK) IN PELINDUNGHEWAN VILLAGE, \\ ASTANAANYAR DISTRICT BANDUNG CITY, WEST JAVA PROVINCE"
}

$T$

The purpose of this study is to analyze the implementation of the Regional Development and Empowerment Innovation Program policy in Pelindunghewan Village, Astanaanyar District, Bandung City and find out the appropriate policy implementation model in the Regional Development and Empowerment Innovation Program in Pelindunghewan Village, Astanaanyar District, Bandung City, Java Province. West.

In completing this thesis, the research uses the theory of E.S. Quade. The researcher used a descriptive research design with a qualitative approach that was used in accordance with the problems to be discussed, the situation and conditions of the local area where this research was conducted. The data collection uses interviews, document analysis, focused discussions or observations that have been stated in field notes.

From the data obtained by researchers related to the realization of the budget for the Regional Development and Empowerment Innovation Program in Pelindunghewan Village, Astanaanyar District, Bandung City, it has not been realized optimally. The Regional Development and Empowerment Innovation Program for Pelindunghewan Village, Astanaanyar District, Bandung City is running less than optimally. This is caused by the first is the dream policy variable where technical instructions and convenience are available in carrying out PIPPK but in reality the community does not understand the proper procedure to carry out PIPPK activities, second is the target groups variable which does not have adequate staff, but staff who some already have competence and are willing to carry out their duties well but have not run optimally due to limited and lack of supervision from the community. Third is the organizational variable that implements it where the Kelurahan is ready to implement PIPPK, Fourth is the Environmental Factor which has been effective in implementation in the social field because with the empowerment of the community it can increase economic development that encapsulates social values.

Keywords: implementation, policy, PIPPK 


\section{Abstrak}

$\mathrm{T}$ ujuan dari penelitian ini adalah untuk Untuk menganalisis implementasi kebijakan Program Inovasi Pembangunan dan Pemberdayaan Kewilayahan di Kelurahan Pelindunghewan Kecamatan Astanaanyar Kota Bandung dan mengetahui model implementasi kebijakan yang cocok dalam Program Inovasi Pembangunan dan Pemberdayaan Kewilayahan di Kelurahan Pelindunghewan Kecamatan Astanaanyar Kota Bandung Provinsi Jawa Barat.

Dalam menyelesaikan tesis ini, penelitian menggunakan teori dari E.S. Quade. Peneliti menggunakan desain penelitian deskriptif dengan pendekatan kualitatif yang digunakan sesuai dengan permasalahan yang akan dibahas, situasi dan kondisi dari lokal di mana penelitian ini dilakukan. Pengumpulan datanya menggunakan cara wawancara, analisis dokumen, diskusi terfokus atau observasi yang telah dituangkan dalam catatan lapangan.

Dari data yang didapat peneliti terkait anggaran realisasi pada kegiatan Program Inovasi Pembangunan dan Pemberdayaan Kewilayahan di Kelurahan Pelindunghewan Kecamatan Astanaanyar Kota Bandung belum terealisasi secara optimal. Program Inovasi Pembangunan dan Pemberdayaan Kewilayahan Kelurahan Pelindunghewan Kecamatan Astanaanyar Kota Bandung berjalan dengan kurang optimal. Hal ini disebabkan oleh Pertama adalah variabel Kebijakan yang diimpikan di mana sudah tersedia petunjuk teknis dan kemudahan dalam menjalankan PIPPK tetapi pada kenyataannya masyarakat belum memahami prosedur yang tepat untuk melaksanakan kegiatan PIPPK, Kedua adalah variabel Kelompok Target di mana belum memiliki staf yang memadai, akan tetapi staf yang ada sudah memiliki kompetensi dan mau untuk melaksanakan tugasnya dengan baik tetapi belum berjalan dengan optimal karena terbatasnya dan kurangnya pengawasan dari masyarakat. Ketiga adalah variabel Organisasi yang melaksanakan di mana Kelurahan sudah siap melaksanakan PIPPK, Keempat adalah Faktor Lingkungan di mana sudah efektif dalam implementasi di bidang sosial karena dengan adanya pemberdayaan pada masyarakat dapat meningkatkan pembangunan ekonomi yang merangkum nilai-nilai sosial.

Kata kunci: implementasi, kebijakan, PIPPK

\section{PENDAHULUAN}

$\mathrm{P}$ embangunan pada hakikatnya merupakan suatu proses yang bersifat integratif, baik dalam tataran perencanaan, pelaksanaan maupun pengendalian yang dilakukan secara berkesinambungan dalam rangka mewujudkan kesejahteraan masyarakat. Mengingat ruang lingkupnya yang sangat luas, kegiatan pembangunan tidak semata-mata menjadi tanggung jawab Pemerintah Daerah melainkan harus dilakukan dan didukung oleh seluruh komponen masyarakat. Oleh karena itu, hubungan kemitraan Pemerintahan Daerah, dan masyarakat merupakan kata kunci yang sangat strategis dan harus menjadi perhatian terutama untuk memecahkan berbagai permasalahan dalam pembangunan.
Program Inovasi Pembangunan dan Pemberdayaan Kewilayahan yang selanjutnya disingkat PIPPK berawal dari pemikiran dan pandangan bahwa perubahanperubahan dinamis yang terjadi di tengah masyarakat dapat dicapai secara optimal apabila ditempuh melalui peran serta dan partisipasi aktif yang luas dari seluruh masyarakat mulai dari tingkat paling bawah terutama dalam pengambilan keputusan dalam memecahkan berbagai permasalahan melalui metode Pemberdayaan Masyarakat.

Program Inovasi Pembangunan dan Pemberdayaan Kewilayahan (PIPPK) tentunya memiliki maksud dan tujuan yang baik dalam bidang pembangunan. Maksud dari program ini adalah untuk meningkatkan tugas, peran dan fungsi aparat kewilayahan beserta seluruh lembaga kemasyarakatan kelurahan dalam rangka 
percepatan pelaksanaan pembangunan melalui pengembangan pemberdayaan masyarakat. Sedangkan tujuan dari program ini adalah untuk mempercepat proses dan pelaksanaan pembangunan khususnya dalam meningkatkan fungsi, kemampuan dan peran kelompok masyarakat di kelurahan untuk menampung, menyalurkan aspirasi, mengoordinasikan sekaligus melaksanakan proses pembangunan yang inovatif secara mandiri melalui metode pemberdayaan masyarakat.

PIPPK Tipe swakelola IV dikelola dan dilaksanakan oleh masyarakat melalui RW (Rukun Warga), PKK (Pemberdayaan dan Kesejahteraan Keluarga), Lembaga Karang Taruna, dan LPM (Lembaga Pemberdayaan Masyarakat) serta kelurahan dan kecamatan. Perencanaan dilakukan oleh RW, PKK, Karang Taruna, dan LPM bersama dengan masyarakat melalui mekanisme Musyawarah Perencanaan Pembangunan (Musrenbang) kelurahan.

Penyerapan anggaran menjadi salah satu tolok ukur dalam keberhasilan pelaksanaan PIPPK ini. Meskipun penyerapan anggaran secara keseluruhan sebesar 89\%, Masih ada satu LKK yang penyerapan anggarannya kurang dari 50\%, yaitu Karang Taruna. Realisasi PIPPK atau penyerapaan anggaran PIPPK di Karang Taruna sebesar 28\%. Sehingga pelaksanaan PIPPK khususnya di Kelurahan Pelindunghewan berdasarkan penyerapan anggarannya dapat dikatakan belum terealisasi sesuai target.

\section{LANDASAN TEORETIS}

Menurut Quade (1984: 310), alasan perlunya implementasi kebijakan adalah untuk menunjukkan bukti bahwa dalam implementasi kebijakan terjadi aksi, interaksi, dan reaksi faktor implementasi kebijakan. Quade menyatakan dalam proses implementasi kebijakan yang ideal akan terjadi interaksi dan reaksi dari organisasi pengimplementasi, kelompok sasaran dan faktor lingkungan yang mengakibatkan munculnya tekanan dan diikuti dengan tindakan tawar-menawar atau transaksi. Melalui transaksi tersebut diperoleh umpan balik yang oleh pengambil kebijakan dapat digunakan sebagai bahan masukan dalam perumusan kebijakan selanjutnya. Quade memberikan gambaran bahwa terdapat empat variabel yang perlu diperhatikan dalam analisis implementasi kebijakan publik, yaitu sebagai berikut.

1. Kebijakan yang diimpikan, yaitu pola interaksi yang diimpikan agar orang yang menetapkan kebijakan berusaha untuk mewujudkan;

2. Kelompok target, yaitu subjek yang diharapkan dapat mengadopsi pola interaksi baru melalui kebijakan dan subjek yang harus berubah untuk memenuhi kebutuhannya;

3. Organisasi yang melaksanakan, yaitu biasanya berupa unit birokrasi pemerintah yang bertanggung jawab mengimplementasikan kebijakan; dan

4. Faktor lingkungan, yaitu elemen sistem dalam lingkungan yang memengaruhi implementasi kebijakan.

\section{METODE PENELITIAN}

\section{Desain Penelitian}

Desain penelitian adalah suatu rencana tentang cara mengumpulkan, mengolah, dan menganalisis data secara sistematis dan terarah agar penelitian dapat dilaksanakan secara efisien dan efektif sesuai dengan tujuannya (Pabundu Tika, 2005: 12).

Guna mencapai tujuan penelitian ini, maka peneliti menetapkan untuk menggunakan metode penelitian dengan pendekatan kualitatif deskriptif. Penelitian deskriptif kualitatif ini bertujuan untuk mendeskripsikan apa-apa yang saat ini berlaku. Di dalamnya terdapat upaya mendeskripsikan, mencatat, analisis dan 
menginterpretasikan kondisi yang sekarang ini terjadi atau ada.

Peneliti menggunakan pendekatan kualitatif deskriptif untuk menggambarkan prosedur atau langkah-langkah peneliti dalam mengkaji implementasi kebijakan Program Inovasi Pembangunan dan Pemberdayaan Kewilayahan dari sudut pandang partisipan, guna mendapatkan gambaran atau deskripsi secara sistematis, faktual, dan akurat mengenai implementasi kebijakan tersebut pada populasi dan tempat penelitian yang ditentukan, yaitu di Kelurahan Pelindunghewan.

Menurut Nazir (2013: 63) bahwa Penelitian deskriptif, yaitu suatu metode dalam meneliti sekelompok manusia, suatu objek, suatu kondisi dan suatu sistem pemikiran pada masa sekarang.

Selanjutnya Sugiyono (2016: 8) mengungkapkan "bahwa metode penelitian kualitatif merupakan metode penelitian naturalistik karena penelitiannya dilakukan pada kondisi yang alamiah (natural setting); disebut sebagai metode kualitatif karena data yang terkumpul dan analisisnya lebih bersifat kualitatif. Penelitian dilakukan pada objek yang alamiah, dengan instrumen adalah orang, yaitu peneliti itu sendiri".

Menurut Moleong (2005: 6) Penelitian kualitatif adalah penelitian yang bermaksud untuk memahami fenomena tentang apa yang dialami oleh subjek penelitian misalnya perilaku, persepsi, motivasi, tindakan, dll secara holistik, dan dengan cara deskripsi dalam bentuk kata-kata dan bahasa, pada suatu konteks khusus yang alamiah dan dengan memanfaatkan berbagai metode alamiah.

\section{Teknik Pengumpulan Data}

Penelitian ini menggunakan jenis wawancara tidak terstruktur untuk pengumpulan data. Peneliti membuat pertanyaan lalu pewawancara dapat menanyakan mengenai pendapat dari terwawancara mengenai objek penelitian. Untuk mendukung hasil pengamatan dan wawancara, maka peneliti akan mengumpulkan data yang kredibel dari dokumen-dokumen yang ada.

Dalam penelitian ini triangulasi yang digunakan, yaitu triangulasi sumber data. Sampai data lengkap kemudian divalidasi dari berbagai sumber sehingga dapat menjadi dasar untuk penarikan simpulan. Dengan teknik ini diharapkan data yang dikumpulkan memenuhi konstruksi penarikan simpulan. Triangulasi ini dilakukan bersamaan dengan kegiatan di lapangan, sehingga peneliti bisa melakukan pencatatan data secara lengkap. Dengan demikian, diharapkan data yang dikumpulkan layak untuk dimanfaatkan.

\section{Teknik Analisis Data}

Aktivitas dalam analisis data dimaksud yang digunakan peneliti dalam menganalisis data hasil penelitian, meliputi:

1. Reduksi Data (Data Reduction)

Mereduksi data dilakukan dengan merangkum, memilih hal-hal yang pokok, memfokuskan pada hal-hal yang penting, dicari tema dan polanya.

2. Penyajian Data (Data Display)

Setelah dilakukan reduksi data, maka selanjutnya mendisplaikan atau menyajikan data, yang dapat dilakukan dengan tabel, grafik, pie chard, pictogram dan sejenisnya. Dengan demikian, maka data terorganisasikan, tersusun dalam pola hubungan, sehingga akan semakin mudah dipahami.

3. Simpulan dan Verifikasi (Conclusion Drawing)

Langkah selanjutnya, yaitu penarikan simpulan dan verifikasi. Simpulan awal yang dikemukakan masih bersifat sementara,dan akan berubah bila tidak ditemukan bukti-bukti yang kuat yang mendukung pada tahap pengumpulan data berikutnya. Tetapi apabila simpulan 
yang dikemukakan pada tahap awal, didukung oleh bukti-bukti yang valid dan konsisten saat peneliti kembali ke lapangan mengumpulkan data, maka simpulan yang dikemukakan merupakan simpulan yang kredibel.

\section{HASIL PENELITIAN DAN PEMBAHASAN}

\section{Implementasi Kebijakan Program Inovasi Pembangunan dan Pember- dayaan Kewilayahan}

Peneliti melakukan wawancara, observasi dan mengambil dokumentasi untuk mengetahui sampai sejauh mana tingkat keberhasilan pelaksanaan atau implementasi kebijakan Program Inovasi Pembangunan dan Pemberdayaan Kewilayahan (PIPPK) di Kelurahan Pelindunghewan Kecamatan Astanaanyar Kota Bandung. Dalam penelitian ini peneliti menggunakan teori yang dikemukakan oleh E.S. Quade, yang menyatakan bahwa implementasi kebijakan dipengaruhi oleh empat variabel, yakni:

1. Kebijakan yang diimpikan, yaitu pola interaksi yang diimpikan agar orang yang menetapkan kebijakan berusaha untuk mewujudkan;

2. Kelompok target, yaitu subjek yang diharapkan dapat mengadopsi pola interaksi baru melalui kebijakan dan subjek yang harus berubah untuk memenuhi kebutuhannya;

3. Organisasi yang melaksanakan, yaitu biasanya berupa unit birokrasi pemerintah yang bertanggung jawab mengimplementasikan kebijakan; dan

4. Faktor lingkungan, yaitu elemen dalam lingkungan yang memengaruhi implementasi kebijakan.

\section{- Kebijakan yang Diimpikan}

Kebijakan yang diimpikan, yaitu ketersediaan petunjuk teknis dan kemudahan dalam melaksanakan PIPPK di Kelurahan Pelindunghewan Kecamatan Astanaanyar dengan tujuan untuk mendorong, memengaruhi dan merangsang untuk melaksanakan. Hasil penelitian yang telah penulis lakukan di daerah. Penulis melakukan wawancara ke lapangan terkait dengan PIPPK di Kelurahan Pelindunghewan Kecamatan Astanaanyar. Untuk mengetahui apakah pelaksanaan PIPPK di Kelurahan Pelindunghewan Kecamatan Astanaanyar peneliti menggali informasi dari beberapa informan. Hasil menunjukkan bahwa sudah ada petunjuk teknis yang jelas dan kemudahan dalam menjalankan program Hal ini berdasarkan dari hasil wawancara dengan Sekretaris Lurah Pelindunghewan Kecamatan Astanaanyar yang menyatakan bahwa:

"Dengan dikeluarkannya Perwalkot No. 15 Tahun 2019, sudah ada patokan dan ukuran untuk melaksanakan Program Inovasi Pembangunan dan Pemberdayaan Kewilayahan (PIPPK) di Kelurahan Pelindunghewan Kecamatan Astanaanyar." (Hasil wawancara, Jumat, 27 maret 2020).

Pernyataan tersebut juga sesuai dengan pernyataan yang dikemukakan oleh Sekretaris Camat Astanaanyar berikut ini.

"Saya rasa Perwalkot No. 15 Tahun 2019 sudah mewakili Program Inovasi Pembangunan dan Pemberdayaan Kewilayahan (PIPPK) dalam hal petunjuk pelaksanaan. Dan saya rasa sudah tersedia dengan jelas petunjuk teknisnya."

Berdasarkan pernyataan tersebut di atas sesuai hasil yang sama menunjukkan bahwa sudah ada petunjuk teknis yang jelas dan kemudahan dalam menjalankan program dengan adanya pernyataan yang dikemukakan oleh Lurah Pelindunghewan yaitu

"Petunjuk teknis dapat kita lihat pada Perwalkot No. 15 Tahun 2019 yang dikeluarkan dari pemerintah. Itu pedoman terbaru termasuk tipe swakelola IV." 
Pandangan dari sudut pandang masyarakat yang melaksanakan PIPPK mengenai adanya ketersediaan petunjuk teknis dan kemudahan dalam melaksanakan PIPPK di Kelurahan Pelindunghewan Kecamatan Astanaanyar yang dikemukakan oleh Ketua RW 08 Kelurahan Pelindunghewan yaitu

"Waktu itu memang kami dikumpulkan di aula kelurahan untuk diberikan pengarahan mengenai aturan baru dalam pelaksanaan PIPPK, di sana dijelaskan mengenai petunjuk teknis dan aturan yang terkait dalam pelaksanaan PIPPK. Tetapi hanya secara lisan yang disampaikannya sehingga kami sering bertanya lagi kepada pegawai kelurahan mengenai petunjuk teknis dalam melaksanakan program."

Dari penjelasan narasumber tersebut bahwa masyarakat belum memahami prosedur yang tepat untuk melaksanakan kegiatan PIPPK.

\section{- Kelompok Target}

Kelompok target, yaitu subjek yang diharapkan dapat mengadopsi pola interaksi baru melalui kebijakan dan subjek yang harus berubah untuk memenuhi kebutuhannya.

Setelah penulis melakukan wawancara ke lapangan terkait dengan PIPPK di Kelurahan Pelindunghewan Kecamatan Astanaanyar didapat hasil sebagai berikut.

Untuk mengetahui pelaksanaan PIPPK di Kelurahan Pelindunghewan Kecamatan Astanaanyar peneliti menggali informasi dari beberapa informan. Hasil menunjukkan bahwa belum mencukupinya Jumlah staf (mencakup kualitas maupun kuantitas) di Kelurahan Pelindunghewan Kecamatan Astanaanyar. Hal ini berdasarkan dari hasil wawancara dengan Camat Astanaanyar yang menyatakan bahwa:

"Kecamatan Astanaanyarbelum memiliki staf yang memadai, akan tetapi staf yang ada sudah memiliki kompetensi dan mau untuk melaksanakan tugasnya dengan baik serta melayani masyarakat dengan sepenuh hati, meskipun hal tersebut harus dilakukan secara langsung, yaitu terjun ke lapangan."

Hal serupa juga dikatakan oleh Lurah Pelindunghewan yang menyatakan bahwa:

"Untuk skill sudah memadai, tetapi kami kekurangan SDM untuk fokus terhadap PIPPK karena melihat banyaknya tugas lain untuk melayanai masyarakat.

Pegawai di Kelurahan Pelindunghewan sebanyak 8 orang, tidak ada seorang pun yang merupakan Tenaga Kontrak Kerja (TKK) dan Tenaga Magang, terdiri dari Pegawai Negeri Sipil (PNS) di kelurahan sebanyak 7 orang dan calon PNS 1 orang.

Peneliti juga menggali infomasi tidak hanya dari pihak kecamatan dan kelurahan, peneliti menggali informasi dari masyarakat yang langsung melaksanakan kebijakan, yaitu Ketua RW 08 Kelurahan Pelindunghewan yang menyatakan bahwa:

"Saya yakin pegawai kelurahan PIPPK sudah memadai skill-nya untuk menjalankan PIPPK, tetapi untuk masyarakat yang menjalankannya saya sendiri pun masih awam untuk urusan administrasi karena harus terus dibimbing dan diawasi oleh pegawai kelurahan agar pelaksanannya berjalan dengan baik."

Selanjutnya yang menjadi indikator peneliti adalah fungsi pengawasan dalam pelaksanaan PIPPK di Kelurahan Pelindunghewan Kecamatan Astanaanyar berdasarkan hasil wawancara dengan Sekretaris Camat Astanaanyar berikut ini.

"Pengawasan pelaksanaan PIPPK di Kelurahan Pelindunghewan Kecamatan Astanaanyar belum berjalan dengan optimal karena terbatasnya dan kurangnya pengawasan dari masyarakat" 
Kemudian berdasarkan hasil wawancara dengan terkait fungsi pengawasan PIPPK di Kelurahan Pelindunghewan Kecamatan Astanaanyar menyatakan bahwa:

"Dari pihak kelurahan tentu memaksimalkan pengawasan apabila program sudah mulai berjalan, tetapi dari masyarakat kurang maksimal karena ke banyak masyarakat harus bekerja sehingga susah untuk mendapatkan waktu yang pas."

Selain itu, wewenang formal dalam implementasi PIPPK di Kelurahan Pelindunghewan Kecamatan Astanaanyar secara garis besar dilaksanakan oleh Aparatur Kelurahan Pelindunghewan dengan memberdayakan seluruh elemen kelurahan yang ada seperti Lembaga Pemberdayaan Masyarakat, Pembina Kesejahteraan Keluarga, Karang Taruna, dan juga masyarakat.

Peneliti juga mendapat informasi dari Ketua RW 05 Kelurahan Pelindunghewan yang menyatakan bahwa:

"Begini Pak, di kelurahan kami memang kami sendiri yang berperan aktif dalam kegiatan ini, jadi kami ikut terlibat dalam program. Bahkan administrasi kami yang melaporkan kepada kelurahan."

Sedangkan fasilitas yang mendukung dalam implementasi PIPPK di Kelurahan Pelindunghewan Kecamatan Astanaanyar cukup mendukung walaupun ada beberapa kekurangan.

\section{- Organisasi Pelaksana}

Organisasi yang melaksanakan, biasanya berupa unit birokrasi pemerintah yang bertanggung jawab mengimplementasikan kebijakan.

Untuk mengetahui pelaksanaan PIPPK di Kelurahan Pelindunghewan Kecamatan Astanaanyar peneliti menggali informasi dari beberapa informan. Hasil menunjukkan bahwa Kelurahan Pelindunghewan
Kecamatan Astanaanyar Kota Bandung Sudah siap untuk melaksanakan PIPPK, tetapi masyarakat sendiri belum terlalu siap.

Hal ini berdasarkan dari hasil wawancara dengan Lurah Pelindunghewan, Kecamatan Astanaanyar yang menyatakan bahwa:

"Kelurahan Pelindunghewan sudah siap dalam melaksanakan PIPPK. Kami memberikan sosialisasi terlebih dahulu kepada staf dan masyarakat sebelum memilih tipe swakelola IV."

Hal serupa juga dikemukakan oleh Kasi Pemerintahan Kelurahan Pelindunghewan yang menyatakan bahwa:

"Tentu kami sangat siap untuk melayani masyarakat, kami selalu berpatokan kepada Perwalkot No. 15 Tahun 2019, para staf yang ditunjuk pun harus selalu berkoordinasi kepada pimpinan dan masyarakat setempat sehingga kami tau kendala apa yang dialami oleh Kelurahan Pelindunghewan."

Peneliti juga mendapat informasi terkait terkait kesiapan dari pihak masyarakat, yaitu anggota PKK Kelurahan Pelindunghewan yang menyatakan bahwa:

"Sebetulnya dari masyarakat sendiri belum terlalu siap karena beberapa dari kami ada yang belum mengerti dalam hal administrasi."

Indikator selanjutnya adalah Ketersediaan anggaran PIPPK di Kelurahan Pelindunghewan Kecamatan Astanaanyar Kota Bandung.

Berdasarkan data di lapangan didapatkan bahwa ketersediaan anggaran dalam PIPPK di Kelurahan Pelindunghewan Kecamatan Astanaanyar Kota Bandung tersedia. Hal ini di kemukakan oleh Camat Kecamatan Astanaanyar yang menyatakan bahwa:

"Ketersediaan anggaran dalam PIPPK sudah ada, tinggal bagaimana masyarakat dapat membuat proposal sesuai dengan 
ketentuan yang berlaku karena kembali lagi kepada program PIPPK type swakelola IV, yaitu masyarakat sendiri yang melaksanakan dari perencanaan sampai ke laporan."

Kemudian peneliti juga mendapatkan informasi dari Ketua RT 5 di Kelurahan Pelindunghewan tentang bagaimana masyarakat mengetahui ketersediaan anggaran pada PIPPK, beliau menyatakan bahwa:

"Kami selalu berkoordinasi terkait anggaran apakah tersedia atau tidak, baru kami membuat proposal kepada kelurahan."

Pengaruh proses pelaksanaan program PIPPK di Kelurahan Pelindunghewan Kecamatan Astanaanyar. Fragmentasi dalam implementasi PIPPK di Kelurahan Pelindunghewan Kecamatan Astanaanyar Kota Bandung sudah dilakukan secara merata oleh Aparatur Kelurahan, yaitu dengan melibatkan setiap lembaga-lembaga di tingkat wilayah seperti karang taruna, PKK, dan LPM. Namun perlu adanya peningkatan koordinasi antara aparatur kelurahan dengan lembaga di tingkat wilayah agar pelaksanaan kebijakan PIPPK dapat berjalan lebih baik pada masa yang akan datang.

Standar operasional prosedur dalam implementasi PIPPK di Kelurahan Pelindunghewan Kecamatan Astanaanyar Kota Bandung sudah dilaksanakan sesuai dengan petunjuk teknis dan prosedur yang berlaku.

\section{- Faktor Lingkungan}

Faktor lingkungan, yaitu elemen dalam lingkungan yang memengaruhi implementasi kebijakan.

Untuk mengetahui pelaksanaan PIPPK di Kelurahan Pelindunghewan Kecamatan Astanaanyar Kota Bandung peneliti menggali informasi dari beberapa informan. Hasil menunjukkan bahwa Implementasi kebijakan di bidang sosial budaya sebagai kondisi sosial yang beragam dalam kehidupan bermasyarakat memerlukan sentuhan kebijakan dan tindak lanjut. Hal ini berdasarkan dari hasil wawancara dengan Camat Astanaanyar yang menyatakan bahwa:

"Karena tidak hanya di bidang ekonomi saja pemberdayaan baiknya dilakukan juga dalam bidang sosial budaya sebab ketika pemberdayaan sosialnya kurang baik akan berdampak juga kepada ekonomi dan lingkungan".

Peneliti juga mendapat infomasi dari Ketua RT 5 di Kelurahan Pelindunghewan yang menyatakan bahwa:

"Untuk pengaruh lebih ke kehidupan sosial ya Pak, dari program yang kami lakukan semua untuk kami masyarakat seperti penampungan air hujan, pembuatan pembatas gang, perbaikan gorong-gorong. Ya terbantulah Pak dengan kami sendiri yang memilih kegiatan yang RT kami perlukan."

Implementasi kebijakan di bidang sosial budaya sebagai kondisi sosial yang beragam dalam kehidupan bermasyarakatmemerlukan sentuhan kebijakan dan tindak lanjut untuk mendukung perbaikan di kehidupan masyarakat. Oleh karena tidak hanya di bidang ekonomi saja pemberdayaan baiknya dilakukan juga dalam bidang sosial budaya sebab ketika pemberdayaan sosialnya kurang baik akan berdampak juga kepada ekonomi dan lingkungan. Karena itu, dalam PIPPK di Kelurahan Pelindunghewan Kecamatan Astanaanyar ikut andil dalam proses pemberdayaan di bidang sosial di antaranya dalam kesehatan dan bantuan sosial. Dengan adanya pemberdayaan pada masyarakat dapat meningkatkan pembangunan ekonomi yang merangkum nilai-nilai sosial.

\section{Teori yang Adaptif dalam PIPPK di Kelurahan Pelindunghewan Kecamatan Astanaanyar.}

Untuk mengetahui keberhasilan sebuah PIPPK, maka perlu diketahui berbagai 
indikator menunjukkan masyarakat berdaya atau tidak. Seluruh program meningkatkan kesejahteraan dalam pengembangan masyarakat yang menekankan pada pendampingan lembaga masyarakat sasaran untuk mengenali dan memahami permasalahannya sendiri serta dapat meningkatkan taraf hidup yang ternilai dalam bertambahnya jumlah pendapatan masyarakat.

Hasil yang telah dicapai dengan adanya program inovasi pembangunan dan pemberdayaan kewilayahan sudah cukup memuaskan, tentunya hal tersebut tercapai atas adanya kerja sama antara pemerintah dan masyarakat kelurahan Pelindunghewan Kecamatan Astanaanyar, tanpa adanya kerja sama antara kedua belah pihak tersebut program ini tidak akan berjalan dengan lancar, meskipun ada beberapa pihak yang merasa kurang maksimal. Tetapi untuk saat ini masyarakat sudah sangat merasakan manfaat dari adanya program tersebut sebab sudah banyak sekali perubahan yang terjadi di kelurahan Pelindunghewan baik di bidang lingkungan, sosial budaya, ekonomi. Keberhasilan di bidang lingkungan dilihat dengan sudah tingginya tingat kesadaran masyarakat terhadap kebersihan, kenyamanan di lingkungan masyarakat.

Upaya yang dilakukan masyarakat yaitu Sosialisasi, dilakukan kepada seluruh aparat kelurahan dan mengundang ketua RW, LPM, PKK dan Karang Taruna serta beberapa tokoh masyarakat. Rembug warga, dalam hal ini bertujuan agar masyarakat bebas dalam memberikan argumen dan menanggapi kegiatan tersebut, selain itu disosialisasikan kembali apa itu PIPPK kepada seluruh masyarakat. Perencanaan program, merencanakan kegiatan apa saja yang akan dilaksanakan baik itu dalam bidang ekonomi, sosial budaya, lingkungan sesuai dengan bidang pemberdayaan PIPPK, kemudian dibuat menjadi sebuah proposal pengajuan kegiatan. Pengawasan, yaitu beberapa orang dari pemerintahan dan seluruh masyarakat yang mengawasi segala bentuk kegiatan atau program yang sedang dilaksanakan. Evaluasi, musyawarah untuk membahas tentang hasil kegiatan yang telah dilaksanakan dan mengeluarkan aspirasi sebagai bahan pelajaran untuk pembangunan ke depannya.

Setelah penulis menyusun penelitian, mengumpulkan data dari informan, dan menyusun hasil penelitian teori yang cocok dalam PIPPK di Kelurahan Pelindunghewan Kecamatan Astanaanyar Kota Bandung Provinsi Jawa Barat adalah teori E.S. Quade.

\section{SIMPULAN}

Implementasi kebijakan Program Inovasi Pembangunan dan Pemberdayaan Kewilayahan (PIPPK) di Kelurahan Pelindunghewan Kecamatan Astanaanyar Kota Bandung Provinsi Jawa Barat berjalan kurang optimal. Hal ini ditandai oleh hal-hal berikut.

\section{Kebijakan yang diimpikan}

Variabel kebijakan yang diimpikan di mana sudah tersedia petunjuk teknis dan kemudahan dalam menjalankan PIPPK tetapi pada kenyataannya masyarakat belum memahami prosedur yang tepat untuk melaksanakan kegiatan PIPPK.

2. Kelompok Target

Variabel kelompok target di mana belum memiliki staf yang memadai, akan tetapi staf yang ada sudah memiliki kompetensi dan mau untuk melaksanakan tugasnya dengan baik tetapi belum berjalan dengan optimal karena terbatasnya dan kurangnya pengawasan dari masyarakat

3. Organisasi yang melaksanakan

Variabel organisasi yang melaksanakan di mana kelurahan sudah siap melaksanakan PIPPK sedangkan untuk masyarakat belum terlalu siap untuk melaksanakan PIPPK. 


\section{Faktor lingkungan}

Faktor lingkungan di mana sudah efektif dalam implementasi di bidang social karena dengan adanya pemberdayaan pada masyarakat dapat meningkatkan pembangunan ekonomi yang merangkum nilai-nilai sosial.

Model implementasi yang adaptif di Kelurahan Pelindunghewan adalah model implementasi E.S. Quade. Hal ini karena:

1. Entitas pemerintah yang dilayani (masyarakat) jaraknya lebih dekat.

2. Respons staf dengan seluruh sumber daya di Kelurahan Pelindunghewan lebih efisien dan efektif menjawab masalah.

3. Kondisi masyarakat dapat menjadi pertimbangan yang lebih fleksibel dari Imlementasi PIPPK.

4. Lingkungan yang kondusif sehingga membantu proses implementasi kebijakan PIPPK

Setelah penulis menyusun penelitian, mengumpulkan data dari informan, dan menyusun hasil penelitian kebijakan yang cocok dalam PIPPK di Kelurahan Pelindunghewan Kecamatan Astanaanyar Kota Bandung Provinsi Jawa Barat adalah teori E.S. Quade.

\section{SARAN}

Berdasarkan simpulan, terdapat beberapa hal yang disarankan oleh peneliti demi perbaikan Program Pembangunan dan Pemberdayaan Kewilayahan (PIPPK) di Kelurahan Pelindunghewan Kecamatan Astanaanyar Kota Bandung Provinsi Jawa Barat. Terdapat aspek-aspek yang belum tersentuh bagi keberhasilan PIPPK sehingga perlu dilakukan:

1. Sosialisasi yang harus sering dilakukan oleh Kelurahan karena masih banyak masyarakat yang belum paham sepenuhnya tentang pedoman dan tata cara dalam pelaksanaan PIPPK.
2. Penambahan staf dalam rangka pengawasan PIPPK agar dapat membimbing para masyarakat.

3. Melengkapi fasilitas-fasilitas penunjang kegiatan agar lebih efisien terhadap pelaksanaan PIPPK.

\section{DAFTAR RUJUKAN}

Abdul, Halim, 2004. Membangun Desa Partisipatif. Jakarta: PT Bumi Aksara.

Abdul Wahab, Solichin. 2012. Analisis Kebijakan: Dari Formulasi ke penyusunan ModelModel Implementasi Kebijakan Publik. Jakarta: PT Bumi Aksara.

Agustino, Leo. 2016. Dasar-dasar kebijakan publik (edisi revisi) Bandung: Alfabeta.

Anggara, Sahya. 2014. Kebijakan Publik. Bandung. Bandung: Pustaka Setia.

Dunn,William N. 2000. Pengantar Analisis Kebijakan Publik. Yogyakarta: Gajah Mada Press.

Harun, Rochajat., \& Ardianto, Elvinaro. 2011. Komunikasi Pembangunan \& Perubahan Sosial: Perspektif Dominan, Kaji Ulang, dan Teori Kritis. Jakarta: Rajawali Pers.

Kusumanegara, Solahuddin. 2010. Model dan Aktor dalam Proses Kebijakan Publik. Yogjakarta: Gava Media.

Moleong, Lexy J. 2005. Metodologi Penelitian Kualitatif. Bandung: PT Remaja Rosdakarya

Moleong, Lexy J. 2014. Metode Penelitian Kualitatif, Edisi Revisi. Bandung: PT Remaja Rosdakarya

Mulyadi, Deddy. 2015. Studi Kebijakan Publik dan Pelayanan Publik. Bandung: Alfabeta.

Nazir, Moh. 2013. Metode Penelitian. Bogor: Ghalia Indonesia.

Popa, Ioan Lala, Gheorghe Preda, dan Monica Boldea. 2010. "A Theoretical Approach Of The Concept Of Innovation" dalam: Journal Managerial Challenges of the Contemporary Society. No. 1. (hlm. 151-156)

Quade, E.S. 1984. Analysis For Public Decisions, Elsevier Science Publisher, New York. 
Subandi. 2011. Ekonomi Pembangunan (cetakan kesatu). Bandung: Alfabeta

Sugiyono. 2013. Metode Penelitian Pendidikan (Pendekatan Kuantitatif, Kualitatif, dan $R \& D)$. Bandung: Alfabeta

Sugiyono. 2015. Metode Penelitian Kombinasi (Mix Methods). Bandung: Alfabeta.

Sugiyono. 2016. Metode Penelitian Pendidikan (Pendekatan Kuantitatif, Kualitatif, dan $R \& D)$. Bandung: Alfabeta.

Suhendra, K. 2006. Peranan Birokrasi dalam Pemberdayaan Masyarakat. Bandung: STKS Press.

Suryabrata, Sumadi. 2008. Psikologi Pendidikan. Raja Grafindo Jakarta: Persada.
Suryani, T. 2008. Perilaku Konsumen; Implikasi Pada Strategi Pemasaran. Yogyakarta: Graha Ilmu.

Sutarno. 2012. Serba-serbi Manajemen Bisnis. Yogyakarta: Graha Ilmu

Tika, Moh. Pabundu. 2005. Metode Penelitian Geografi. Jakarta: Bumi Aksara.

Todaro, Michael P. 2000. Pembangunan Ekonomi di Dunia Ketiga. Jakarta: Erlangga.

Tresiana, Novita dan Duaji, Noverman. 2017. Implementasi dan Evaluasi Kebijakan Publik. Yogyakarta: Suluh Media.

Zubaedi. 2007. Wacana Pembangun Alternatif: Ragam Prespektif Pembangunan dan Pemberdayaan Masyarakat. Jakarta: $\mathrm{Ar}$ Ruzz Media. 
Virioner - Vol. $13 \backslash$ No. $2 \backslash$ Agustus 2021 